\title{
Reinventing Chinese public health after a SARS (Severe Acute Respiratory Syndrome)/Coronavirus epidemic
}

\section{Reinventando a saúde pública chinesa após uma epidemia de SARS (Severe Acute Respiratory Syndrome)/Coronavírus}

\author{
Jonatan Sacramento ${ }^{i}$ \\ ' Doctoral student, Universidade Estadual de Campinas. \\ Campinas - SP - Brasil \\ orcid.org/0000-0003-2018-7696 \\ jonatansacramento@gmail.com \\ Maria Conceição da Costai \\ ii Professor, Universidade Estadual de Campinas. \\ Campinas - SP - Brasil \\ orcid.org/0000-0002-7439-890X \\ dacosta@ige.unicamp.br
}

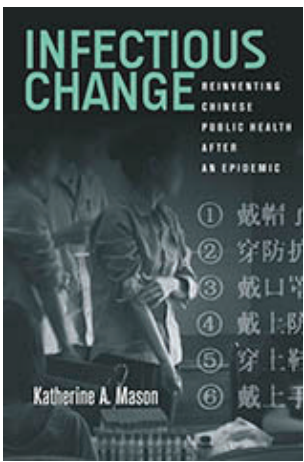

MASON, Katherine A. Infectious change: reinventing Chinese public health after an epidemic. Stanford: Stanford University Press. 2016. 272p.
R etween 2002 and 2003, a coronavirus epidemic broke out in B China and spread across the world, infecting more than 8,000 people and causing approximately $10 \%$ of this contingent to die. In the months when the Severe Acute Respiratory Syndrome (SARS) was active in China, severe sanitary measures were adopted, such as quarantines, isolation, the closing of public places, the use of large-scale diagnostic tests, and the construction of isolated health units in record time. The world has witnessed very similar protocols in China's current fight against the SARS-Cov-2 epidemic in 2020.

The 2002-2003 epidemic drastically changed the structure of China's health services. And the book Infectious change: reinventing Chinese public health after an epidemic, by Katherine A. Mason, published in 2016 by Stanford University Press, was written to bring to light and analyze these transformations and their impacts on public health in that country.

In this groundbreaking piece of ethnography, Mason shows how changes to the Chinese public health system were driven not only by the SARS epidemic, but through massive investments to create the Chinese Center for Disease Control and Prevention (CCDC). Envisaged as the equivalent of the American CDC in Asia, the Chinese organization was designed not only for epidemic prevention and epidemiological control, but also as a major center of research in the area.

Oriented by reflections from health anthropology and insights from the social studies of science, Mason anchors her arguments on the ideas of knowledge production and scientific 
networks. Like Sheila Jasanoff (2004), we hold that there can be no scientific knowledge without adequate social support. In this sense, national and transnational networks and institutions of scientific knowledge, and its circulation, can be understood as proposed by Ilana Löwy (2004), first edition in 2001, not mentioned by Mason: that scientific knowledge, its production conditions, and its political and administrative features cannot be dissociated from one another, but must be evaluated in conjunction with the context in which they were produced.

One particular value of Mason's book is the way it highlights how technical, bureaucratic, and social conditions were instrumental in shaping the endeavor to end the epidemic. Whilst it would have been interesting if a more detailed analysis had been provided of the technical and scientific production on epidemics and the health protocols that the members of the CCDC produced, to which the author had access, according to the book's list of bibliographic references, it provides a comprehensive ethnography of health and its intersections with State processes.

That said, in the course of over four chapters, Mason shows how the implementation and functioning of the centers were permeated by issues related to professional prestige, intellectual expertise, and the networks of relationships that forged the health experiences (locally and globally), as well as the health protocols and scientific practices in public health in the context studied - a large city near Hong Kong, given the fictitious name of "Tianmai" by the author.

The focus of the first two chapters is on the tensions not only between "modernity" and "tradition," but also between "Western" and "Eastern," and how these materialized in the daily practices of CCDC professionals when dealing with the local population who should be governed - as opposed to their expected public (their cosmopolitan peers). Composed mostly of seasonal migrant workers from the countryside, the population of Tianmai was out of step with the cosmopolitan image the technicians constructed of the "ideal" patient.

In the second chapter, the relationship between the health professionals and the Tianmai population is analyzed through the regimes of truth and trust. For Mason, the Chinese public health actions were based on guanxi, or "interpersonal mutual aid connections" (according to Pinheiro-Machado, 2011). With the advent of CCDC and the change in the profile of the professionals working in health and epidemiological surveillance, a discourse of professionalization, based on criteria of rationality, truth and effectiveness, was recommended for these new professionals at the time of making and implementing health actions. However, this ended up colliding with "traditional" relationships, based on the language of guanxi, which jeopardized the effectiveness of the center's health activities.

Following this same tension between "tradition" and "modernity," the third chapter of the book is dedicated to thinking about the history of public health in Tianmai since the introduction of CCDC and the efforts of the new professionals to become fully-fledged members of the international scientific community. From the discussion about doing science based on tests and analyses of human inputs, Mason shows how the CCDC's professionals' adoption of the Western ideas of data reliability and strong science based on empirical evidence implied questions involving the ethics of scientific practice, free and informed 
consent, changes in local protocols and doctor/patient relationships, and ultimately a whole new way of thinking about clinical practice and experimental science as a whole.

These questions, introduced in chapter three, are unpicked in the form of a conclusion in the fourth chapter, entitled "Pandemic betrayals." From the context of the H1N1 pandemic in 2009, the author analyzes the Chinese public health professionals' responses to the epidemic as they attempted to prove they were bona fide members of the international scientific community.

However, as Mason points out, Tianmai's professionals were themselves seen by their foreign peers as the source of the epidemic, because they felt the methods the Chinese CCDC adopted to contain swine influenza were inadequate. Indeed, foreign health professionals saw the Chinese staff less as peers and more as members of the population that needed assistance.

Mason's ethnography sheds light not only on situations of transnational epidemics, but also on aspects of institutional, racial, moral, and scientific prestige involved in controlling or ending epidemics. For understanding health in situations of crisis and adversity and for a critical look at global health actions (Brown, Cueto, Fee, 2006), Katherine Mason's book is a valuable reference.

\section{REFERENCES}

BROWN, Theodore M.; CUETO, Marcos; FEE, Elizabeth.

A transição de saúde pública "internacional" para "global" e a Organização Mundial da Saúde. História, Ciências, Saúde - Manguinhos, v.13, n.3, p.623-647. 2006.

JASANOFF, Sheila.

The idiom of co-production. In: Jasanoff, Sheila (Org.). States of knowledge: the co-production of science and social order. New York: Routledge. p.1-12. 2004.
LÖWY, Ilana.

Vírus, mosquitos e modernidade: a febre amarela no Brasil, entre ciência e política. Rio de Janeiro: Fiocruz. 2004.

MASON, Katherine A.

Infectious change: reinventing Chinese public health after an epidemic. Stanford: Stanford University Press. 2016.

PINHEIRO-MACHADO, Rosana.

Fazendo guanxi: dádivas, etiquetas e emoções na economia da China pós-Mao. Mana, v.17, n.1, p.99-130. 2011. 